\title{
Common Fixed Point Results in G-Metric Spaces and Applications
}

\author{
Meenakshi Gugnani \\ Sh. L.N. Hindu College \\ Rohtak-124001(INDIA).
}

\author{
Madhu Aggarwal \\ Department of Mathematics, \\ Maharshi Dayanand University \\ Rohtak-124001(INDIA).
}

\author{
Renu Chugh \\ Department of Mathematics, \\ Maharshi Dayanand University \\ Rohtak-124001(INDIA)
}

\begin{abstract}
A common fixed point theorem using EA-property for four weakly compatible maps is obtained in the setting of Gmetric spaces without exploiting the notion of continuity. Our results generalize the results of Abbas and Rhoades[7], and Manro et. al.[11]. Moreover, we show that these maps satisfy property R. Applications to certain intergral equations and functional equations are also obtained.
\end{abstract}

\section{Key words}

Common fixed Point, G- Metric Spaces, $\Phi$-maps, Weakly Compatible Maps, E. A. property, Property R.

\section{INTRODUCTION AND PRELIMINARIES}

In 2006, Mustafa and Sims [15] introduced a new notion of generalized metric spaces called G-metric spaces. Later on several authors obtained some fixed point results under various contractive conditions in G-metric spaces (see[7], [8], [10], [11], [14]).

The aim of this paper is to prove a fixed point theorem using EA-property for four weakly compatible maps (without exploiting the notion of continuity) in G- metric spaces. A major benefit of the "E.A. property" is that it ensures convergence of desired sequences without completeness. Our results generalize the results of Abbas and Rhoades[7], and Manro et. al.[11]. We also establish property $\mathrm{R}$ for these maps. An interesting fact about maps satisfying property $\mathrm{R}$ is that they have no nontrivial periodic points. Some papers dealing with property $\mathrm{R}$ are ([1], [3], [4]). At the end, applications regarding the existence and uniqueness of solutions of certain class of integral equations and functional equations are also obtained.

Now, we give some definitions and results that will be needed in the sequel:

Definition 1.1.[15] Let $X$ be a nonempty set and let $G: X \times X$ $\times \mathrm{X} \rightarrow \mathrm{R}^{+}$a function satisfying the following axioms:

(G1) $\mathrm{G}(\mathrm{x}, \mathrm{y}, \mathrm{z})=0$ if $\mathrm{x}=\mathrm{y}=\mathrm{z}$,

(G2) $0<\mathrm{G}(\mathrm{x}, \mathrm{x}, \mathrm{y})$ for all $\mathrm{x}, \mathrm{y} \in \mathrm{X}$ with $\mathrm{x} \neq \mathrm{y}$,

(G3) $G(x, x, y) \leq G(x, y, z)$, for all $x, y, z \in X$, with $z \neq y$,

(G4) $\mathrm{G}(\mathrm{x}, \mathrm{y}, \mathrm{z})=\mathrm{G}(\mathrm{x}, \mathrm{z}, \mathrm{y})=\mathrm{G}(\mathrm{y}, \mathrm{z}, \mathrm{x})=\cdots$ (symmetry in all the three variables),

(G5) $\mathrm{G}(\mathrm{x}, \mathrm{y}, \mathrm{z}) \leq \mathrm{G}(\mathrm{x}, \mathrm{a}, \mathrm{a})+\mathrm{G}(\mathrm{a}, \mathrm{y}, \mathrm{z})$, for all $\mathrm{x}, \mathrm{y}, \mathrm{z}, \mathrm{a} \in$ $\mathrm{X}$, (rectangle inequality).

Then the function $\mathrm{G}$ is called a generalized metric, or, more specifically a $G$-metric on X, and the pair $(\mathrm{X}, \mathrm{G})$ is called a $\mathrm{G}$ metric space.

Definition 1.2[15]. Let $(X, G)$ be a G-metric space, let $\left\{x_{n}\right\}$ be a sequence of points of $\mathrm{X}$, we say that $\left\{\mathrm{x}_{\mathrm{n}}\right\}$ is $G$-convergent to $\mathrm{x}$ if $\lim _{n, m \rightarrow \infty} G\left(x, x_{n}, x_{m}\right)=0$; that is, for any $\varepsilon>0$, there exists $\mathrm{k} \epsilon \mathbf{N}$ such that $\mathrm{G}\left(\mathrm{x}, \mathrm{x}_{\mathrm{n}}, \mathrm{x}_{\mathrm{m}}\right)<\varepsilon$, for all $\mathrm{n}, \mathrm{m} \geq \mathrm{k}$ (throughout this paper we mean by $\mathbf{N}$ the set of all natural numbers). We call $x$ the limit of the sequence and write $x_{n}$ $\rightarrow \mathrm{x}$ or $\lim \mathrm{x}_{\mathrm{n}}=\mathrm{x}$.

Proposition1.3[15].Let (X, G) be a G-metric space. Then the following are equivalent:

(1) $\left\{x_{n}\right\}$ is G-convergent to $x$,

(2) $\mathrm{G}\left(\mathrm{x}_{\mathrm{n}}, \mathrm{x}_{\mathrm{n}}, \mathrm{x}\right) \rightarrow 0$, as $\mathrm{n} \rightarrow \infty$,

(3) $\mathrm{G}\left(\mathrm{x}_{\mathrm{n}}, \mathrm{x}, \mathrm{x}\right) \rightarrow 0$, as $\mathrm{n} \rightarrow \infty$,

(4) $\mathrm{G}\left(\mathrm{x}_{\mathrm{m}}, \mathrm{x}_{\mathrm{n}}, \mathrm{x}\right) \rightarrow 0$, as $\mathrm{m}, \mathrm{n} \rightarrow \infty$.

Definition 1.4[15]. Let $(\mathrm{X}, \mathrm{G})$ be a G-metric space. A sequence $\left\{\mathrm{x}_{\mathrm{n}}\right\}$ is called $G$-Cauchy if for each $\varepsilon>0$, there is k $\in N$ such that $\mathrm{G}\left(\mathrm{x}_{\mathrm{n}}, \mathrm{x}_{\mathrm{m}}, \mathrm{x}_{l}\right)<\varepsilon$, for all $\mathrm{n}, \mathrm{m}, l \geq \mathrm{k}$, that is, if $\mathrm{G}\left(\mathrm{x}_{\mathrm{n}}, \mathrm{x}_{\mathrm{m}}, \mathrm{x}_{l}\right) \rightarrow 0$ as $\mathrm{n}, \mathrm{m}, l \rightarrow \infty$.

Proposition 1.5[15]. Let (X, G) be a G-metric space, then the following conditions are equivalent:

(1) The sequence $\left\{x_{n}\right\}$ is G-Cauchy.

(2) For every $\varepsilon>0$, there exists $\mathrm{k} \in \mathrm{N}$ such that $\mathrm{G}\left(\mathrm{x}_{\mathrm{n}}, \mathrm{x}_{\mathrm{m}}\right.$, $\left.\mathrm{x}_{\mathrm{m}}\right)<\varepsilon$, for all $\mathrm{n}, \mathrm{m} \geq \mathrm{k}$.

Proposition 1.6[15]. Let $(X, G)$ be a G-metric space. Then $\mathrm{f}$ : $\mathrm{X} \rightarrow \mathrm{X}$ is G-continuous at $\mathrm{x} \in \mathrm{X}$ if and only if it is Gsequentially continuous at $\mathrm{x}$, that is, whenever $\left\{\mathrm{x}_{\mathrm{n}}\right\}$ is $\mathrm{G}$ convergent to $\mathrm{x},\left\{\mathrm{f}\left(\mathrm{x}_{\mathrm{n}}\right)\right\}$ is G-convergent to $\mathrm{f}(\mathrm{x})$.

Proposition 1.7[15]. Let $(X, G)$ be a G-metric space. Then the function $\mathrm{G}(\mathrm{x}, \mathrm{y}, \mathrm{z})$ is jointly continuous in all the three of its variables.

Definition 1.8[15].A G-metric space $(\mathrm{X}, \mathrm{G})$ is called $G$ complete if every G-Cauchy sequence is $\mathrm{G}$-convergent in $(\mathrm{X}$, G).

Proposition 1.9[15] Let $(X, G)$ be a G-metric space. Then for any $\mathrm{x}, \mathrm{y}, \mathrm{z}, \mathrm{a} \in \mathrm{X}$ it follows that:

(1) $G(x, y, z)=0$, then $x=y=z$,

(2) $\mathrm{G}(\mathrm{x}, \mathrm{y}, \mathrm{z}) \leq \mathrm{G}(\mathrm{x}, \mathrm{x}, \mathrm{y})+\mathrm{G}(\mathrm{x}, \mathrm{x}, \mathrm{z})$,

(3) $\mathrm{G}(\mathrm{x}, \mathrm{y}, \mathrm{y}) \leq 2 \mathrm{G}(\mathrm{y}, \mathrm{x}, \mathrm{x})$,

(4) $\mathrm{G}(\mathrm{x}, \mathrm{y}, \mathrm{z}) \leq \mathrm{G}(\mathrm{x}, \mathrm{a}, \mathrm{z})+\mathrm{G}(\mathrm{a}, \mathrm{y}, \mathrm{z})$,

(5) $\mathrm{G}(\mathrm{x}, \mathrm{y}, \mathrm{z}) \leq \frac{2}{3}(\mathrm{G}(\mathrm{x}, \mathrm{y}, \mathrm{a})+\mathrm{G}(\mathrm{x}, \mathrm{a}, \mathrm{z})+\mathrm{G}(\mathrm{a}, \mathrm{y}, \mathrm{z}))$,

(6) $\mathrm{G}(\mathrm{x}, \mathrm{y}, \mathrm{z}) \leq(\mathrm{G}(\mathrm{x}, \mathrm{a}, \mathrm{a})+\mathrm{G}(\mathrm{y}, \mathrm{a}, \mathrm{a})+\mathrm{G}(\mathrm{z}, \mathrm{a}, \mathrm{a}))$

Example 1.10[15]. Let $(X, d)$ be a usual metric space, then $\left(\mathrm{X}, \mathrm{G}_{\mathrm{S}}\right)$ and $\left(\mathrm{X}, \mathrm{G}_{\mathrm{m}}\right)$ are $\mathrm{G}$-metric spaces, where

$\mathrm{G}_{\mathrm{S}}(\mathrm{x}, \mathrm{y}, \mathrm{z})=\mathrm{d}(\mathrm{x}, \mathrm{y})+\mathrm{d}(\mathrm{y}, \mathrm{z})+\mathrm{d}(\mathrm{x}, \mathrm{z})$, for all $\mathrm{x}, \mathrm{y}, \mathrm{z} \in \mathrm{X}$, $\mathrm{G}_{\mathrm{m}}(\mathrm{x}, \mathrm{y}, \mathrm{z})=\max \{\mathrm{d}(\mathrm{x}, \mathrm{y}), \mathrm{d}(\mathrm{y}, \mathrm{z}), \mathrm{d}(\mathrm{x}, \mathrm{z})\}$, for all $\mathrm{x}, \mathrm{y}, \mathrm{z} \in$ $\mathrm{X}$.

Definition 1.11. Denote by $\Phi$ the set of non-decreasing continuous functions $\phi: \mathrm{R}^{+} \rightarrow \mathrm{R}^{+}$satisfying:

(1) $\phi(0)=0$,

(2) $0<\phi(t)<t$ for all $\mathrm{t}>0$,

(3) the series $\sum_{n \geq 1} \phi^{n}(t)$ converges for all $\mathrm{t}>0$. 
From now unless otherwise stated we mean by $\phi$ a $\Phi$-map.

Definition 1.12[2] Two self mappings $f$ and $g$ are said to be weakly compatible if they commute at coincidence points.

Definition 1.13. Let $\left\{T_{i}\right\}$ be a sequence of selfmaps of a Gmetric space $\mathrm{X}$. We shall say that this family has property $R$ if

$\cap_{i} F\left(T_{i}\right)=\cap_{i} F\left(T_{i}^{n}\right)$.

In 2002, Amari and Moutawakil [9] introduced a generalization of non compatible maps as E.A. property in metric spaces. We shall study E.A. property in the frame work of G-metric spaces as follows:

Definition 1.14 Let $\mathrm{X}$ be a G-metric space and $\mathrm{S}$ and $\mathrm{T}$ be two self mappings of $\mathrm{X}$. Then $\mathrm{S}$ and $\mathrm{T}$ are said to satisfy $E$. $A$.

property if there exists a sequence $\left\{\mathrm{x}_{\mathrm{n}}\right\}$ such that $\lim _{n \rightarrow \infty} \mathrm{Sx}_{\mathrm{n}}=$

$\lim _{n \rightarrow \infty} \mathrm{Tx}_{\mathrm{n}}=\mathrm{t}$

for some $\mathrm{t} \in \mathrm{X}$.

Example1.15. Let $X=[0,1]$. Define $S, T: X \rightarrow X$ by $T x=\frac{x}{2}$ and $\mathrm{S} \mathrm{x}=\frac{x}{8}$, for all $\mathrm{x}$ in $\mathrm{X}$. Consider the sequence $\mathrm{x}_{\mathrm{n}}=\frac{1}{n}$. Clearly, $\lim _{n \rightarrow \infty} \mathrm{Sx}_{\mathrm{n}}=\lim _{n \rightarrow \infty} \mathrm{Tx}_{\mathrm{n}}=0$. Then $\mathrm{S}$ and $\mathrm{T}$ satisfy E.A. property. Example1.16. Let $X=[3,+\infty)$. Define $S, T: X \rightarrow X$ by $T x=$ $x+2$ and $S x=3 x+2$, for all $x$ in $X$. Suppose that the E.A. property holds. Then, there exists in $\mathrm{X}$ a sequence $\left\{\mathrm{x}_{\mathrm{n}}\right\}$ satisfying $\lim _{n \rightarrow \infty} \mathrm{Sx}_{\mathrm{n}}=\lim _{n \rightarrow \infty} \mathrm{Tx}_{\mathrm{n}}=\mathrm{t}$ for some $\mathrm{t}$ in X. Therefore, $\lim _{n \rightarrow \infty} \mathrm{x}_{\mathrm{n}}=\mathrm{t}$-2and $\lim _{n \rightarrow \infty} \mathrm{x}_{\mathrm{n}}=\frac{t-2}{3}$ Thus, $\mathrm{t}=2$, which is a contradiction, since 2 is not contained in $\mathrm{X}$. Hence $\mathrm{S}$ and $\mathrm{T}$ do not satisfy E.A. property.

\section{FIXED POINT RESULTS.}

Theorem 2.1 Let $X$ be a G-metric space. Suppose the maps A, B, S, T : X $\rightarrow X$ satisfies for all $\mathrm{x}, \mathrm{y} \in \mathrm{X}$

$\mathrm{G}(\mathrm{Sx}, \mathrm{Ty}, \mathrm{Ty}) \leq \phi(\mathrm{G}(\mathrm{Ax}, \mathrm{By}, \mathrm{By}))$

or

$$
\mathrm{G}(\mathrm{Sx}, \mathrm{Sx}, \mathrm{Ty}) \leq \phi(\mathrm{G}(\mathrm{Ax}, \mathrm{Ax}, \mathrm{By}))
$$

where $\phi \in \Phi$. If the maps A, B, S and T satisfy the following conditions:

1. $\overline{T X} \subseteq A X$ and $\overline{S X} \subseteq B X$

2. the pair $(A, S)$ or $(B, T)$ satisfies $E$. A. property.

3. the pair (A, S) or (B, T) are weakly compatible,

then $\mathrm{A}, \mathrm{B}, \mathrm{S}$ and $\mathrm{T}$ have a unique common fixed point.

Proof. Suppose that the mappings A, B, S and T satisfy

(2.1.1) and the pair $(B, T)$ satisfy E. A. property. Then there exists a sequence $\left\{x_{n}\right\}$ in $X$ such that

(2.1.3) $\lim _{n \rightarrow \infty} B \mathrm{~B}_{\mathrm{n}}=\lim _{n \rightarrow \infty} \mathrm{Tx}_{\mathrm{n}}=\mathrm{t}$ for some $\mathrm{t} \in \mathrm{X}$.

Since $\overline{T X} \subseteq A X$ then there exist a $\left\{\mathrm{y}_{\mathrm{n}}\right\}$ in $\mathrm{X}$ such that

$\mathrm{Tx}_{\mathrm{n}}=A \mathrm{y}_{\mathrm{n}}$. Hence $\lim _{n \rightarrow \infty} \mathrm{Ay}_{\mathrm{n}}=\mathrm{t}$. First, we prove that

$\lim _{n \rightarrow \infty} S y_{n}=t$. In view of (2.1.1), we have

$$
\mathrm{G}\left(\mathrm{Sy}_{\mathrm{n}}, \mathrm{Tx}_{\mathrm{n}}, \mathrm{Tx}_{\mathrm{n}}\right) \leq \phi\left(\mathrm{G}\left(\mathrm{Ay}_{\mathrm{n}}, \mathrm{Bx}_{\mathrm{n}}, \mathrm{Bx}_{\mathrm{n}}\right)\right) .
$$

Taking $\mathrm{n} \rightarrow \infty$ we get

$\lim _{n \rightarrow \infty} \mathrm{G}\left(\mathrm{Sy}_{\mathrm{n}}, \mathrm{t}, \mathrm{t}\right) \leq \phi(\mathrm{G}(\mathrm{t}, \mathrm{t}, \mathrm{t}))=\phi(0)=0$.
This implies $\quad \lim _{n \rightarrow \infty} \mathrm{G}\left(\mathrm{Sy}_{\mathrm{n}}, \mathrm{t}, \mathrm{t}\right)=0$,

which gives $\quad \lim _{n \rightarrow \infty} S y_{n}=t$.

Since $\mathrm{t} \in \overline{T X}$ and $\overline{T X} \subseteq A X$, there exists an element $\mathrm{u} \in$ $\mathrm{X}$ such that $\mathrm{Au}=\mathrm{t}$

Subsequently,

$\lim _{n \rightarrow \infty} \mathrm{Bx}_{\mathrm{n}}=\lim _{n \rightarrow \infty} \mathrm{Tx}_{\mathrm{n}}=\lim _{n \rightarrow \infty} \mathrm{Ay}_{\mathrm{n}}=\lim _{n \rightarrow \infty} \mathrm{Sy}_{\mathrm{n}}=\mathrm{Au}$.

Using (2.1.1), $\mathrm{G}\left(\mathrm{Su}, \mathrm{Tx}_{\mathrm{n}}, \mathrm{Tx}_{\mathrm{n}}\right) \leq \phi\left(\mathrm{G}\left(\mathrm{Au}, \mathrm{Bx}_{\mathrm{n}}, \mathrm{Bx}_{\mathrm{n}}\right)\right)$.

Taking $\mathrm{n} \rightarrow \infty$, yields

$\mathrm{G}(\mathrm{Su}, \mathrm{Au}, \mathrm{Au}) \leq \phi(\mathrm{G}(\mathrm{Au}, \mathrm{Au}, \mathrm{Au}))=\phi(0)=0$, implies that $\mathrm{G}(\mathrm{Su}, \mathrm{Au}, \mathrm{Au})=0$, which gives $\mathrm{Su}=\mathrm{Au}$.

Since $\overline{S X} \subseteq B X$,then there exists $\mathrm{v} \in \mathrm{X}$ such that $\mathrm{Su}=\mathrm{Bv}$.

We claim that $\mathrm{Bv}=\mathrm{Tv}$. Using (2.1.1),

$\mathrm{G}(\mathrm{Bv}, \mathrm{Tv}, \mathrm{Tv})=\mathrm{G}(\mathrm{Su}, \mathrm{Tv}, \mathrm{Tv}) \leq \phi(\mathrm{G}(\mathrm{Au}, \mathrm{Bv}, \mathrm{Bv}))$

$=\phi(\mathrm{G}(\mathrm{Au}, \mathrm{Au}, \mathrm{Au}))=\phi(0)=0$.

This implies $\mathrm{G}(\mathrm{Bv}, \mathrm{Tv}, \mathrm{Tv})=0$, which gives, $\mathrm{Bv}=\mathrm{Tv}$. Therefore, we obtain $\mathrm{Au}=\mathrm{Su}=\mathrm{Bv}=\mathrm{Tv}=\mathrm{t}$.

Since $(\mathrm{A}, \mathrm{S})$ and $(\mathrm{B}, \mathrm{T})$ are weakly compatible. Then $\mathrm{ASu}=$ $\mathrm{SAu}$ and $\mathrm{BTv}=\mathrm{TBv}$. Using (2.1.4), we have

$$
\mathrm{At}=\mathrm{St} \text { and } \mathrm{Bt}=\mathrm{Tt} \quad \text { (2.1.5) }
$$

Thus, $\mathrm{t}$ is common coincidence point of A, B, S and T. Now, we show that $\mathrm{St}=\mathrm{t}$. Using (2.1.1),

$\mathrm{G}(\mathrm{St}, \mathrm{Tv}, \mathrm{Tv}) \leq \phi(\mathrm{G}(\mathrm{At}, \mathrm{Bv}, \mathrm{Bv}))$.

From (2.1.4) and (2.1.5) we get

$\mathrm{G}(\mathrm{St}, \mathrm{t}, \mathrm{t}) \leq \phi(\mathrm{G}(\mathrm{St}, \mathrm{t}, \mathrm{t}))<\mathrm{G}(\mathrm{St}, \mathrm{t}, \mathrm{t})$

This implies $\mathrm{G}(\mathrm{St}, \mathrm{t}, \mathrm{t})=0$, which gives, $\mathrm{St}=\mathrm{t}$.

Hence, $\mathrm{At}=\mathrm{St}=\mathrm{t}$.

Now, we show that $\mathrm{Tt}=\mathrm{t}$. Using (2.1.1), we have

$\mathrm{G}(\mathrm{Su}, \mathrm{Tt}, \mathrm{Tt}) \leq \phi(\mathrm{G}(\mathrm{Au}, \mathrm{Bt}, \mathrm{Bt}))$.

From (2.1.4) and (2.1.5) we get

$\mathrm{G}(\mathrm{t}, \mathrm{Tt}, \mathrm{Tt}) \leq \phi(\mathrm{G}(\mathrm{t}, \mathrm{Tt}, \mathrm{Tt}))<\mathrm{G}(\mathrm{t}, \mathrm{Tt}, \mathrm{Tt})$.

This implies $\mathrm{G}(\mathrm{t}, \mathrm{Tt}, \mathrm{Tt})=0$, which gives, $\mathrm{Tt}=\mathrm{t}$.

Hence $\mathrm{Tt}=\mathrm{t}=\mathrm{Bt}$. Thus, $\mathrm{t}$ is common fixed point of $\mathrm{A}, \mathrm{B}, \mathrm{S}$ and T. If the pair $(A, S)$ satisfy E. A. property, we obtain the similar result.

Uniqueness, Let $\mathrm{w}$ be another common fixed point of A, B, S and T. Then, using (2.1.1), we have

$\mathrm{G}(\mathrm{t}, \mathrm{w}, \mathrm{w})=\mathrm{G}(\mathrm{St}, \mathrm{Tw}, \mathrm{Tw}) \leq \phi(\mathrm{G}(\mathrm{At}, \mathrm{Bw}, \mathrm{Bw})$

$$
=\phi(\mathrm{G}(\mathrm{t}, \mathrm{w}, \mathrm{w}))<\mathrm{G}(\mathrm{t}, \mathrm{w}, \mathrm{w}) \text {. }
$$

Thus, $\quad \mathrm{G}(\mathrm{t}, \mathrm{w}, \mathrm{w})=0$, which implies that, $\mathrm{t}=\mathrm{w}$.

The proof using (2.1.2) is similar.

Corollary 2.2. Let $X$ be a G-metric space. Suppose the maps A, B, S, T : X $\rightarrow X$ satisfies:

$$
\mathrm{G}(\mathrm{Sx}, \mathrm{Ty}, \mathrm{Ty}) \leq \mathrm{qG}(\mathrm{Ax}, \mathrm{By}, \mathrm{By})
$$

or

$$
\mathrm{G}(\mathrm{Sx}, \mathrm{Sx}, \mathrm{Ty}) \leq \mathrm{qG}(\mathrm{Ax}, \mathrm{Ax}, \mathrm{By})
$$

for all $\mathrm{x}, \mathrm{y} \in \mathrm{X}$ where $q \in[0,1)$. If the maps $\mathrm{A}, \mathrm{B}, \mathrm{S}$ and $\mathrm{T}$ satisfy the following conditions:

1. $\overline{T X} \subseteq A X$ and $\overline{S X} \subseteq B X$,

2. the pair (A, S) or (B, T) satisfies E. A. property,

3. the pair (A, S) or (B, T) are weakly compatible,

then $\mathrm{A}, \mathrm{B}, \mathrm{S}$ and $\mathrm{T}$ have a unique common fixed point.

Proof: Define $\phi:[0, \infty) \rightarrow[0, \infty)$ by $\phi(t)=q t$.

Then, it is clear that $\phi \in \Phi$.. So, the result follows from Theorem 2.1 . 
Corollary 2.3. Let $\mathrm{X}$ be a G-metric space. Suppose the maps A, $S: X \rightarrow X$ satisfies for all $\mathrm{x}, \mathrm{y} \in \mathrm{X}$ :

$$
\mathrm{G}(\mathrm{Sx}, \mathrm{Sy}, \mathrm{Sy}) \leq \phi(\mathrm{G}(\mathrm{Ax}, \mathrm{Ay}, \mathrm{Ay}))
$$

or

$$
\mathrm{G}(\mathrm{Sx}, \mathrm{Sx}, \mathrm{Sy}) \leq \phi(\mathrm{G}(\mathrm{Ax}, \mathrm{Ax}, \mathrm{Ay}))
$$

where $\phi \in \Phi$. If the maps $\mathrm{A}$ and $\mathrm{S}$ satisfy the following conditions:

\section{1. $\overline{S X} \subseteq B X$}

2. the pair (A, S) satisfy E. A. property.

3. the pair $(A, S)$ is weakly compatible,

then $\mathrm{A}$ and $\mathrm{S}$ have a unique common fixed point.

Proof: Follows from Theorem 2.1 by taking $\mathrm{S}=\mathrm{T}$ and $\mathrm{A}=\mathrm{B}$. Special case of above result is Theorem 2.1 of [11]

Corollary 2.4. Let $\mathrm{X}$ be a complete G-metric space. Suppose the maps $S: X \rightarrow X$ satisfy one of the following conditions:

$$
\mathrm{G}(\mathrm{Sx}, \mathrm{Sy}, \mathrm{Sy}) \leq \phi((\mathrm{G}(\mathrm{x}, \mathrm{y}, \mathrm{y}))
$$

$$
\mathrm{G}(\mathrm{Sx}, \mathrm{Sx}, \mathrm{Sy}) \leq \phi(\mathrm{G}(\mathrm{x}, \mathrm{x}, \mathrm{y}))
$$

for all $\mathrm{x}, \mathrm{y} \in \mathrm{X}$, where $\phi \in \Phi$. Then $\mathrm{S}$ has a unique fixed point.

Proof: Follows from Theorem 2.1 by taking $\mathrm{S}=\mathrm{T}$ and $\mathrm{A}=\mathrm{B}$ $=\mathrm{I}($ Identity mapping $)$

Special case of above result is Theorem 2.1 of [7]

Corollary 2.5. Let X be a complete G-metric space. Suppose the maps $\mathrm{S}: \mathrm{X} \rightarrow \mathrm{X}$ satisfy one of the following conditions: $\mathrm{G}(\mathrm{Sx}, \mathrm{Sy}, \mathrm{Sy}) \leq q((\mathrm{G}(\mathrm{x}, \mathrm{y}, \mathrm{y}))$

or

$$
\mathrm{G}(\mathrm{Sx}, \mathrm{Sx}, \mathrm{Sy}) \leq q(\mathrm{G}(\mathrm{x}, \mathrm{x}, \mathrm{y}))
$$

for all $\mathrm{x}, \mathrm{y} \in \mathrm{X}$, where $q \in[0,1)$. Then $\mathrm{S}$ has a unique fixed point.

The following example illustrates Theorem 2.1 .

Example. 3.6. Let $X=[2,20]$. Define A, B, S, T : $X \rightarrow X$ by $\mathrm{Sx}=2$ if $\mathrm{x}=2$ or $\mathrm{x}>5 ; \mathrm{Sx}=6$ if $2<\mathrm{x}<5$,

$B x=2$ if $x=2$ or $x>5 ; B x=12$ if $2<x \leq 4 ; B x=6$ if $4<x \leq 5$,

$\mathrm{Tx}=2$ if $\mathrm{x}=2$ or $\mathrm{x}>4$; $\mathrm{Tx}=4$ if $2<\mathrm{x}<4$,

$A x=2$ if $x=2$ or $x>7, A x=16$ if $2<x \leq 4, A x=5$ if $5<x<7, A x=4$ if $x=7$.

Then, (1) $\overline{T X} \subseteq A X$ and $\overline{S X} \subseteq B X$,

(2) the pair $(A, S)$ satisfy E. A. property with $x_{n}=7+1 / n$ or $(B, T)$ satisfy $E$. A. property with $x_{n}=5+1 / n$

(3) the pair $(\mathrm{A}, \mathrm{S})$ and $(\mathrm{B}, \mathrm{T})$ are weakly compatible,

Define G: $\mathrm{X} \times \mathrm{X} \times \mathrm{X} \rightarrow \mathrm{R}^{+}$by

$\mathrm{G}(\mathrm{x}, \mathrm{y}, \mathrm{z})=\max \{|x-y|,|y-z|,|z-x|\}$ Then $(\mathrm{X}, \mathrm{G})$ is $\mathrm{G}-$ complete.

Also define $\phi:[0, \infty) \rightarrow[0, \infty)$ as $\phi(\mathrm{t})=\frac{t}{2}$. Then $\mathrm{A}, \mathrm{B}, \mathrm{S}$,

$\mathrm{T}$ and $\emptyset$ satisfies all the hypothesis of Theorem 2.1 . Here 2 is the unique common fixed point of $\mathrm{A}, \mathrm{B}, \mathrm{S}$ and $\mathrm{T}$.

Remark. The maps A, B, S, and T are discontinuous even at the common fixed point $\mathrm{x}=2$.

\section{PROPERTY R}

In this section, we shall show that maps satisfying (2.1.1) or (2.1.2) possess property $\mathrm{R}$.

Theorem 3.1. Under the conditions of Theorem 2.1, A, B, S and $\mathrm{T}$ have property $\mathrm{R}$.

Proof. From Theorem 2.1, A, B, S and T has a fixed point. Therefore, $\mathrm{F}\left(\mathrm{A}^{\mathrm{m}}\right) \cap \mathrm{F}\left(\mathrm{B}^{\mathrm{m}}\right) \cap \mathrm{F}\left(\mathrm{S}^{\mathrm{m}}\right) \cap \mathrm{F}\left(\mathrm{T}^{\mathrm{m}}\right) \neq \varnothing$ for each positive integer $\mathrm{m}$. Let $\mathrm{m}>1$ and suppose that $\mathrm{p} \in \mathrm{F}\left(\mathrm{A}^{\mathrm{m}}\right) \cap$ $\mathrm{F}\left(\mathrm{B}^{\mathrm{m}}\right) \cap \mathrm{F}\left(\mathrm{S}^{\mathrm{m}}\right) \cap \mathrm{F}\left(\mathrm{T}^{\mathrm{m}}\right)$.
We claim that $p \in F(A) \cap F(B) \cap F(S) \cap F(T)$. Then , for any positive integer i,l,r,t satisfying $1 \leq \mathrm{i}, \mathrm{l}, \mathrm{r}, \mathrm{t} \leq \mathrm{m}$, and using (2.1.1), we get

(3.1.1) $\quad \mathrm{G}\left(\mathrm{S}^{\mathrm{i}} \mathrm{A}^{\mathrm{j}} \mathrm{p}, \mathrm{T}^{\mathrm{k}} \mathrm{B}^{\mathrm{l}} \mathrm{p}, \mathrm{T}^{\mathrm{k}} \mathrm{B}^{\mathrm{l}} \mathrm{p}\right)$

$$
\begin{aligned}
& \leq \phi\left(\mathrm{G}\left(\mathrm{A}\left(\mathrm{S}^{\mathrm{i}-1} \mathrm{~A}^{\mathrm{j}} \mathrm{p}, \mathrm{B}\left(\mathrm{T}^{\mathrm{k}-1} \mathrm{~B}^{1} \mathrm{p}\right), \mathrm{B}\left(\mathrm{T}^{\mathrm{k}-1} \mathrm{~B}^{1} \mathrm{p}\right)\right)\right)\right. \\
& =\phi\left(\mathrm{G}\left(\mathrm{S}^{\mathrm{i}-1} \mathrm{~A}^{\mathrm{j}+1} \mathrm{p}, \mathrm{T}^{\mathrm{k}-1} \mathrm{~B}^{1+1} \mathrm{p}, \mathrm{T}^{\mathrm{k}-1} \mathrm{~B}^{1+1} \mathrm{p}\right)\right) \leq \delta,
\end{aligned}
$$

where $\delta=\max _{1 \leq i, j, k, l \leq m} \mathrm{G}\left(\mathrm{S}^{\mathrm{i}} \mathrm{A}^{\mathrm{j}} \mathrm{p}, \mathrm{T}^{\mathrm{k}} \mathrm{B}^{\mathrm{l}} \mathrm{p}, \mathrm{T}^{\mathrm{k}} \mathrm{B}^{\mathrm{l}} \mathrm{p}\right)$.

Assume $\delta>0$, then using (3.1.1), we obtain

$\delta \leq \phi(\delta)<\delta$, which is a contradiction. Therefore $\delta=0$, which implies that

$\mathrm{G}(\mathrm{Sp}, \mathrm{p}, \mathrm{p})=\mathrm{G}(\mathrm{Ap}, \mathrm{p}, \mathrm{p})=\mathrm{G}(\mathrm{p}, \mathrm{Tp}, \mathrm{Tp})=\mathrm{G}(\mathrm{p}, \mathrm{Bp}, \mathrm{Bp})=0$.

This implies that $\mathrm{Sp}=\mathrm{Ap}=\mathrm{Tp}=\mathrm{Bp}=\mathrm{p}$.

Hence $p \in F(A) \cap F(B) \cap F(S) \cap F(T)$. Thus $A, B, S$ and $\mathrm{T}$ have property $\mathrm{R}$.

\section{APPLICATION TO INTEGRAL EQUATIONS}

The existence of solutions of Integral equations has been studied by several authors (see [5], [6]). In this section we prove an existence of a solution for a certain non-linear integral equation in G-metric space using corollary 2.5 .

Consider the integral equation:

$u(t)=\int_{0}^{T} K(t, s, u(s)) d s+h(t), \quad \mathrm{t} \in[0, \mathrm{~T}]$

where $\mathrm{T}>0$. Let $\mathrm{X}=\mathrm{C}([0, \mathrm{~T}])$ be the set of all continuous functions defined on $[0, \mathrm{~T}]$.

Define $\mathrm{G}: \mathrm{X} \times \mathrm{X} \times \mathrm{X} \rightarrow \mathrm{R}^{+}$by

$$
\begin{aligned}
G(x, y, z)= & \sup _{t \in[0, T]}|x(t)-y(t)|+\sup _{t \in[0, T]}|y(t)-z(t)| \\
& +\sup _{t \in[0, T]}|z(t)-x(t)|,
\end{aligned}
$$

Then $(\mathrm{X}, \mathrm{G})$ is $\mathrm{G}$-complete metric space. Now we prove the existence of the solution of the integral equation (4.1.1).

Theorem.4.1 Suppose the following assumptions hold:

(a) $\mathrm{K}:[0, \mathrm{~T}] \times[0, \mathrm{~T}] \times \mathrm{R} \rightarrow \mathrm{R}$ and $\mathrm{h}: \mathrm{R} \rightarrow \mathrm{R}$ are continuous

(b) There exist a continuous function $\mathrm{G}:[0, \mathrm{~T}] \times[0, \mathrm{~T}] \rightarrow \mathrm{R}^{+}$ such that

$$
|K(t, s, u)-K(t, s, v)| \leq G(t, s)|u-v|
$$

for each $u, v \in R$ and $s, t \in[0, T]$.

(c) $\sup _{t \in[0, T]} \int_{0}^{T} G(t, s) d s \leq q$ for some $\mathrm{q} \in[0,1)$.

Then the integral equation (4.1.1) has a solution $\mathrm{u} \in \mathrm{X}$.

Proof. Define S: $\mathrm{X} \rightarrow \mathrm{X}$ by

$$
S x(t)=\int_{0}^{T} K(t, s, x(s)) d s+h(t), \quad \mathrm{t} \in[0, \mathrm{~T}] .
$$

For $\mathrm{x}, \mathrm{y} \in \mathrm{X}$, we have

$$
\begin{aligned}
& G(S x, S y, S y)=2 \sup _{t \in[0, T]}|S x(t)-S y(t)| \\
& =2 \sup _{t \in[0, T]}\left|\int_{0}^{T}(K(t, s, x(s))-K(t, s, y(s))) d s\right|
\end{aligned}
$$




$$
\begin{aligned}
& \leq 2 \sup _{t \in[0, T]} \int_{0}^{T}|K(t, s, x(s))-K(t, s, y(s)) d s| \\
& \leq 2 \sup _{t \in[0, T]}|x(t)-y(t)| \sup _{t \in[0, T]} \int_{0}^{T} G(t, s) d s \\
& =G(x, y, y) \sup _{t \in[0, T]} \int_{0}^{T} G(t, s) d s \leq q .
\end{aligned}
$$

By using condition (c), there is a $\mathrm{q} \in[0,1)$ such that

$$
\begin{gathered}
\sup _{t \in[0, T]} \int_{0}^{T} G(t, s) d s \leq q . \text { Then, we have } \\
\mathrm{G}(\mathrm{Sx}, \mathrm{Sy}, \mathrm{Sy}) \leq q G(x, y, y) .
\end{gathered}
$$

Thus all the required hypothesis of corollary 2.5 are satisfied and hence there exists a continuous solution $\mathrm{u} \in \mathrm{X}$ of the integral equation (4.1.1).

\section{APPLICATION TO FUNCTIONAL EQUATIONS}

The existence and uniqueness of solutions of functional equations arising in dynamic programming have been studied by various authors (see [12], [13]). In this section we prove existence and uniqueness of a solution for a class of functional equations in G-metric space using corollary 2.5.

Let $\mathrm{U}$ and $\mathrm{V}$ be Banach spaces, $\mathrm{W} \subset \mathrm{U}, \mathrm{D} \subset \mathrm{V}$ and $R$ is the field of real numbers. Let $X=B(W)$ denote the set of all bounded real valued functions on W. Define $\mathrm{G}: \mathrm{X} \times \mathrm{X} \times$ $\mathrm{X} \rightarrow \mathrm{R}^{+}$by $\mathrm{G}(\mathrm{x}, \mathrm{y}, \mathrm{z})=\max \{d(x, y), d(y, z), d(z, x)\}$, where $\mathrm{d}: \mathrm{X} \times \mathrm{X} \rightarrow \mathrm{R}^{+}$is defined as

$$
\mathrm{d}(\mathrm{x}, \mathrm{y})=\sup _{t \in W}\{|x(t)-y(t)|\}
$$

then $(\mathrm{X}, \mathrm{G})$ is $\mathrm{G}$-complete metric space. Consider the following functional equation

$$
\mathrm{p}(\mathrm{x})=\sup _{y \in D}\{g(x, y)+M(x, y, p(\tau(x, y)))\},
$$

where $\mathrm{g}: \mathrm{W} \times D \rightarrow R$ and $\mathrm{M}: \mathrm{W} \times D \times \mathrm{R} \rightarrow R$ are bounded functions. We consider $\mathrm{W}$ and $\mathrm{D}$ as the state and decision spaces, respectively, $\tau: W \times D \rightarrow W$ represents transformation of the process and $\mathrm{p}(\mathrm{x})$ represents the optimal return function with initial state $x$. Now we prove the existence and uniqueness of the solution of the functional equation (5.1.1).

Theorem 5.1 Suppose that there exists a $q \in[0,1)$ such that for every

$$
\begin{aligned}
& (\mathrm{x}, \mathrm{y}) \in \mathrm{W} \times D, \mathrm{~h}_{1}, \mathrm{~h}_{2} \in \mathrm{X}, \mathrm{t} \in \mathrm{W} \text {, the inequality } \\
& \left|M\left(x, y, h_{1}(t)\right)-M\left(x, y, h_{2}(t)\right)\right| \leq q\left|h_{1}(t)-h_{2}(t)\right|
\end{aligned}
$$

holds, then the functional equation (5.1.1) has a unique bounded solution in $\mathrm{X}$.

Proof Define S: $X \rightarrow X$ by

$$
\mathrm{S}(\mathrm{h}(\mathrm{x}))=\sup _{y \in D}\{g(x, y)+M(x, y, h(\tau(x, y)))\}
$$

where $\mathrm{x} \in \mathrm{W}, \mathrm{h} \in \mathrm{X}$
Let $\lambda$ be an arbitrary positive real number and $h_{1}, h_{2} \in X$. For $\mathrm{x} \in \mathrm{W}$, we choose

$\mathrm{y}_{1}, \mathrm{y}_{2} \in \mathrm{D}$ so that

$\mathrm{S}\left(\mathrm{h}_{1}(\mathrm{x})\right)<\mathrm{g}\left(\mathrm{x}, \mathrm{y}_{1}\right)+\mathrm{M}\left(\mathrm{x}, \mathrm{y}_{1}, \mathrm{~h}_{1}\left(\tau_{1}\right)\right)+\lambda$,

$\mathrm{S}\left(\mathrm{h}_{2}(\mathrm{x})\right)<\mathrm{g}\left(\mathrm{x}, \mathrm{y}_{2}\right)+\mathrm{M}\left(\mathrm{x}, \mathrm{y}_{2}, \mathrm{~h}_{2}\left(\tau_{2}\right)\right)+\lambda$

where $\tau_{1}=\tau\left(\mathrm{x}, \mathrm{y}_{1}\right)$ and $\tau_{2}=\tau\left(\mathrm{x}, \mathrm{y}_{2}\right)$.

From the definition of mapping $\mathrm{S}$, we have

$\mathrm{S}\left(\mathrm{h}_{1}(\mathrm{x})\right) \geq \mathrm{g}\left(\mathrm{x}, \mathrm{y}_{2}\right)+\mathrm{M}\left(\mathrm{x}, \mathrm{y}_{2}, \mathrm{~h}_{1}\left(\tau_{2}\right)\right)$,

$\mathrm{S}\left(\mathrm{h}_{2}(\mathrm{x})\right) \geq \mathrm{g}\left(\mathrm{x}, \mathrm{y}_{1}\right)+\mathrm{M}\left(\mathrm{x}, \mathrm{y}_{1}, \mathrm{~h}_{2}\left(\tau_{1}\right)\right)$,

Now, from $(5.1 .2),(5.1 .4)$ and $(5.1 .7)$, we obtain

$$
\begin{aligned}
& S\left(h_{1}(x)\right)-S\left(h_{2}(x)\right) \\
& <M\left(x, y, h\left(\tau_{1}\right)\right)-M\left(x, y, h\left(\tau_{2}\right)\right)+\lambda \\
& \leq\left|M\left(x, y, h_{1}\left(\tau_{1}\right)\right)-M\left(x, y, h_{2}\left(\tau_{2}\right)\right)\right|+\lambda \\
& \leq q\left|h_{1}(x)-h_{2}(x)\right|+\lambda
\end{aligned}
$$

Similarly, from (5.1.2), (5.1.5) and (5.1.6), we obtain

$$
S\left(h_{2}(x)\right)-S\left(h_{1}(x)\right) \leq q\left|h_{1}(x)-h_{2}(x)\right|+\lambda
$$

Hence from (5.1.8) and (5.1.9) we have

$$
\left|S\left(h_{1}(x)\right)-S\left(h_{2}(x)\right)\right| \leq q\left|h_{1}(x)-h_{2}(x)\right|+\lambda
$$

Since the inequality (5.1.10) is true for all $\mathrm{x} \in \mathrm{W}$ and arbitrary $\lambda>0$, then we have

$\mathrm{G}\left(\mathrm{Sh}_{1}, \mathrm{Sh}_{1}, \mathrm{Sh}_{2}\right) \leq \mathrm{qG}\left(\mathrm{h}_{1}, \mathrm{~h}_{1}, \mathrm{~h}_{2}\right)$.

Thus all the conditions of corollary 2.5 are satisfied for the mapping $\mathrm{S}$ and hence the functional equation (5.1.1) has a unique bounded solution.

\section{CONCLUSION}

In this study we obtained common fixed point results in a Gmetric space without using stronger conditions like continuity of the mappings involved and completeness of the space. Thus our results improve and extend many recent results existing in the literature. An important consequence of our results is that none of these maps has nontrivial periodic points. Applications regarding the existence of solutions of certain integral equations and functional equations are also discussed.

\section{REFERENCES}

[1] Rhoades, B. E. and Abbas, M., Maps satisfying generalized contractive condition of integral type for which $\mathrm{F}(\mathrm{T})=\mathrm{F}\left(\mathrm{T}^{\mathrm{n}}\right)$, Int. J. of Pure and Applied Math., vol. 45, No. 2 (2008), 225-231.

[2] Jungck, G.and Rhoades, B. E., Fixed point for set valued functions without continuity, Indian J. Pure and Appl. Math., 29(1998), 227-238.

[3] Jeong, G. S. and Rhoades, B. E., Maps for which $\mathrm{F}(\mathrm{T})=$ $\mathrm{F}\left(\mathrm{T}^{\mathrm{n}}\right)$, Fixed point theory and applications, vol. 6 , (2004), 71-105.

[4] Jeong, G. S. and Rhoades, B. E., More maps for which $\mathrm{F}(\mathrm{T})=\mathrm{F}\left(\mathrm{T}^{\mathrm{n}}\right)$, Demonstratio Mathematica, vol. XL, no. 3, (2007), 671-680.

[5] Altun, I. and Simsek, H., Some fixed point theorems on ordered metric spaces and application, Fixed Point Theory and Applications, Volume 2010, Article ID 6214469, (2010), 17 pages. 
[6] Nieto, J. J., An abstract monotone iterative technique, Nonlinear Analysis: Theory Methods and Applications, 28 (1997), 1923-1933.

[7] Abbas, M.and Rhoades, B. E., Common fixed point results for noncommuting mappings without continuity in generalized metric spaces, Applied Math. and Comp.,215 (2009), 262-269.

[8] Abbas, M., Khan, S. H. and Nazir, T. Common fixed points of R-weakly commuting maps in generalized metric spaces, Fixed Point Theory and Appl., Volume 2011 (41),(2011), 11 pages.

[9] Aamri, M. and Moutawakil, D. El. , Some new common fixed point theorems under strict contractive conditions , J. Math. Anal. Appl., 270(2002), 181-188.

[10] Chugh, R., Kadian, T., Rani, A. and Rhoades, B. E., Property P in G-metric spaces, Fixed Point Theory and App., Volume 2010, Article ID 401684, (2010),12 pages.
[11] Manro, S., Bhatia, S. S. and Kumar, S., Expansion Mapping Theorems In G-metric spaces, Int. J. Contemp.Math. Sciences, Vol. 5, no. 51, (2010), 2529 2535.

[12] Singh, S. L. and Mishra, S. N., Remarks on recent fixed point theorems, Fixed Point Theory and Appl., Volume 2010, Article ID 452905,(2010), 18 pages.

[13] Singh, S. L. and Mishra, S. N., Coincidence theorems for certain classes of hybrid contractions, Fixed Point Theory and Appl., Vol. 2010, Article ID 898109, (2010), 14 pages.

[14] Mustafa, Z., Obiedat, H. and Awawdeh, F., Some fixed point theorem for mapping on complete G-metric spaces, Fixed Point Theory and Appl., Vol. 2008, Article ID 189870,(2008), 12pages.

[15] Mustafa, Z., and Sims, B., A new approach to generalized metric spaces, Journal of Nonlinear and Convex Analysis, vol. 7, no. 2, (2006), 289-297. 